\title{
Vitamin E protects from lipid peroxidation during winter stress in the seagrass Cymodocea nodosa
}

\author{
Sergi Munné-Bosch ${ }^{1,2} \oplus \cdot$ Sandra Puig $^{1} \cdot$ Erola Fenollosa $^{1,2} \cdot$ Andrea Casadesús $^{1,2} \cdot$ Estrella Fernández $^{1}$
}

Received: 29 November 2021 / Accepted: 7 January 2022 / Published online: 17 January 2022

(c) The Author(s) 2022

\begin{abstract}
Main conclusion Adjustments in the antenna size and $\alpha$-tocopherol contents provide protection from sustained damage in leaves of a seagrass, while low vitamin $E$ contents appear to be enough to protect rhizomes (which appear to be more cold tolerant than leaves).
\end{abstract}

\begin{abstract}
Despite low temperatures can adversely affect the proper growth and development of marine angiosperms, by, among other processes, increasing reactive oxygen species production and causing oxidative damage to lipid membranes, the role of vitamin E in seagrasses, such as Cymodocea nodosa has not been explored thus far. Here, we aimed to better understand the possible role of this chain-breaking (peroxyl radical-trapping) antioxidant in response to low temperatures, and most particularly in relation to the occurrence of photo-inhibition and lipid peroxidation. Low temperatures caused an important desiccation of leaves, but not of rhizomes, which were much more tolerant to cold stress than leaves. Cold stress during winter was associated with chlorophyll loss and transient photo-inhibition, as indicated by reversible reductions in the $F_{\mathrm{v}} / F_{\mathrm{m}}$ ratio. Adjustments in pigment antenna size and vitamin $\mathrm{E}$ contents per unit of chlorophyll during winter may help protect the photosynthetic apparatus from sustained photo-inhibitory damage and lipid peroxidation events in leaves. Rhizomes also accumulated significant amounts of vitamin E, although to a much lesser extent than leaves, and kept protected from lipid peroxidation during winter, as indicated by malondialdehyde contents, a product from secondary lipid peroxidation. It is concluded that vitamin $\mathrm{E}$ can help protect both leaves and rhizomes from lipid peroxidation, although cold stress during winter can cause transient photo-inhibition of the photosynthetic apparatus, in C. nodosa.
\end{abstract}

Keywords Antioxidants · Cold stress $\cdot$ Lipid hydroperoxides $\cdot$ Low temperatures $\cdot$ Malondialdehyde $\cdot$ Marine angiosperms . Tocopherols

\section{Abbreviations}

$\alpha$-toc $\alpha$-Tocopherol

Chl Chlorophyll

$F_{\mathrm{v}} / F_{\mathrm{m}} \quad$ Maximum efficiency of PSII photochemistry

LOOH Lipid hydroperoxides

Communicated by Dorothea Bartels.

Sergi Munné-Bosch

smunne@ub.edu

1 Department of Evolutionary Biology, Ecology and Environmental Sciences, University of Barcelona, Av. Diagonal 643, 08028 Barcelona, Spain

2 Research Institute of Biodiversity (IrBio), Faculty of Biology, University of Barcelona, Av. Diagonal 643, 08028 Barcelona, Spain
MDA Malondialdehyde

ROS Reactive oxygen species

\section{Introduction}

Marine prairies are widely distributed in all but coastal areas of the world, except around the polar regions. They occupy an area of $3.45 \times 10^{5} \mathrm{~km}^{2}$ which represents up to $0.1-0.2 \%$ of total coastal oceans (Banerjee et al. 2018), being one of the most productive ecosystems which are found in coastal areas (Bracun 2016). In addition, they play an important role in the trophic network and provide many goods and services to society (Barbier et al. 2011). Furthermore, marine prairies are bio-constructive ecological ecosystems providing habitat to many species for feeding, reproduction and protection and therefore incorporate a great biological diversity (Hemminga 
and Duarte 2000). On the other hand, they participate in the carbon cycle by capturing a high amount of carbon dioxide, act as sediment stabilizers and improve sedimentation or particulate matter (Bracun 2016). The lattice structure of rhizomes from these plants allows stabilizing the substrate, helps reduce the effects of erosion of coastline and regression of beaches, and reduces the hydrodynamics of currents and waves (Van der Heide et al. 2012; Pérez et al. 2015).

In the last 50 years, due to the increase in anthropogenic pressures on these ecosystems, an increase in losses of marine prairies has been observed in both tropical and temperate regions (Orth et al. 2006). It has been estimated that the rate of decline of marine prairies on a global scale reached 1\% per year before 1940 and 5\% per year after 1980 (Waycott et al. 2009). Acceleration of its degradation and decrease on a global scale results from a combination of different pressures arising from human activity: climate change (e.g., increase in temperature, sea level rise, increase in frequency and intensity of drastic climatic events), alteration of water quality, increase in nutrients, sediments and pollutants, destruction of plants by commercial fishing practices and boat anchorages, destruction of habitat for construction of human infrastructure, regeneration of beaches or introduction of non-native species, among others (Boudouresque et al. 2009; Romero et al. 2015).

Plants growing under optimal conditions are constantly producing reactive oxygen species (ROS) as part of the correct functioning of their aerobic metabolism (Hasanuzzaman et al. 2020), and the presence of ROS at low concentrations, it is important because they are involved in signaling networks deployed to activate various physiological processes (Xie et al. 2019). ROS are one of the most important components of the signaling cascade activated by plants in response to cold, and its sustained production is essential for the correct regulation of gene expression under stressful conditions (Yadav 2010). However, when produced at high concentrations in a sustained manner, ROS can cause peroxidation of lipid membranes, protein oxidation, enzyme inactivation, nucleic acid damage and even lead to cell death (KriegerLiszkay and Trebst 2006). Thylakoids are very prone to lipid peroxidation since chloroplasts function at high oxygen tensions and in the light, so that photooxidative processes due an absorption of excess of energy can easily occur (Asada 2006). Although they are also generated in other compartments as in mitochondria, peroxisomes, plasma membrane and cell wall (Hasanuzzaman et al. 2020), ROS produced in chloroplasts can be one of the main causes of cell death if not eliminated by antioxidants.

One of the most important chloroplastic antioxidants is $\alpha$-tocopherol ( $\alpha$-toc), which belongs to the vitamin E group of compounds. $\alpha$-Tocopherol, which is the major vitamin $\mathrm{E}$ form present in photosynthetic tissues, is made of an aromatic ring with a hydroxyl group (chromanol), which readily reacts with lipid peroxyl radicals and ROS (mainly singlet oxygen), and a long hydrophobic chain (polyprenoid chain), which anchor the molecule to the thylakoid membrane (Krieger-Liszkay and Trebst 2006; Falk and Munné-Bosch 2010; Muñoz and Munné-Bosch 2019; Hasanuzzaman et al. 2020). $\alpha$-Tocopherol efficiently eliminates singlet oxygen both by (physical) quenching and (chemical) scavenging, and it is the only antioxidant present in plant cells capable of inhibiting the propagation of lipid peroxidation, so its function within chloroplasts is essential to protect thylakoids from lipid peroxidation (Muñoz and Munné-Bosch 2019). $\beta$-Carotene can help $\alpha$-toc in protecting the photosynthetic apparatus from singlet oxygen (Trebst 2003) and ascorbate is essential to recycle $\alpha$-tocopheroxyl radicals, which are the products of the action of $\alpha$-toc scavenging lipid peroxyl radicals (Munné-Bosch and Alegre 2002; Kanwischer et al. 2005). The function of $\alpha$-toc as an inhibitor of photo-inhibition and in maintaining the stability of the lipid membranes has been studied in cyanobacteria and terrestrial plants (Havaux et al. 2005; Inoue et al. 2011; Kumar et al. 2021), but to our knowledge, no studies have been performed thus far on its role in marine angiosperms.

Marine angiosperms are grouped into four different families (Posidoniaceae, Cymodoceaceae, Zosteraceae and Hydrocharitaceae) that converged with the development of different adaptations for marine life. Nowadays, Cymodocea nodosa is one of the most representative marine plant species in the Mediterranean Sea that belongs to this group of higher plants of terrestrial origin that colonized the middle sea about 100 million years ago (Pérez et al. 2015). Here, we aimed at better understanding mechanisms underlying cold stress tolerance in $C$. nodosa, with a focus on studying the involvement of vitamin $\mathrm{E}$ in the protection from lipid peroxidation both in photosynthetic tissues (leaves) and non-photosynthetic tissues (rhizomes). We hypothesized that vitamin E might accumulate in leaves, but not in rhizomes, in response to winter stress to specifically protect the photosynthetic apparatus from cold-induced photo-oxidative stress.

\section{Materials and methods}

\section{Plant material and sampling}

The study was carried out in the Alfacs Bay at the Ebro delta in the north-eastern coast of Spain, in the province of Tarragona, Catalonia (NE Spain, 40 35' 48.8' N $0^{\circ} 42^{\prime} 52.2^{\prime \prime} \mathrm{E}$ ). Alfacs Bay, where C. nodosa is the dominant marine angiosperm species, is an estuarine embayment in the coast that is shallow (maximum depth $6 \mathrm{~m}$ ) and is closed to the Mediterranean Sea by a long, narrow sand bar dominated by nutrient inputs from channels collecting the runoff from 
neighboring rice paddy fields (Pérez et al. 1994). Samples were collected from $C$. nodosa plants found in the shallowest areas (more specifically at $2 \mathrm{~m}$ depth) during February 25th (winter), June 3rd (spring) and August 1st (summer) 2019. All samplings were always performed on fully expanded young leaves and rhizomes of 15 plants (at least $2 \mathrm{~m}$ apart) on sunny days at midday. In addition, every day of sampling, measurements of the environmental conditions of the water (temperature, $\mathrm{pH}$, and conductivity) were taken. For each individual five leaves and five pieces of rhizome were taken, avoiding the ends and extracting all epiphytes before measurements. All samples were frozen with liquid nitrogen and stored at $-80{ }^{\circ} \mathrm{C}$ until analyses. In addition, a leaf and a piece of rhizome were additionally separated from each individual in a falcon tube with water from the study area and kept in the dark to estimate the leaf hydration and $F_{\mathrm{v}} / F_{\mathrm{m}}$ ratio upon arrival to the laboratory.

\section{Leaf hydration, chlorophyll contents and $F_{\mathrm{v}} / F_{\mathrm{m}}$ ratio}

Upon arrival to the laboratory (around $3 \mathrm{~h}$ from samplings), samples were weighed with a precision balance to obtain the fresh mass. Then, chlorophyll fluorescence was measured in leaves (which previously adapted to darkness for $3 \mathrm{~h}$ ) using a mini-PAM (Walz, Effeltrich, Germany) and the maximum efficiency of PSII photochemistry $\left(F_{\mathrm{v}} / F_{\mathrm{m}}\right.$ ratio $)$ estimated following van Kooten and Snel (1990). Both foliar and rhizome samples were then dried at $70{ }^{\circ} \mathrm{C}$ to constant weight to measure the dry mass. Leaf hydration $(H)$ was then calculated as (fresh mass - dry mass)/dry mass. For pigment estimation, frozen samples were grounded and repeatedly extracted with methanol containing $0.01 \%$ butylated hydroxytoluene (BHT; w/v), using vortex for $20 \mathrm{~s}$ followed by 30 min of ultra-sonication (Bransonic ultrasonic bath 2800, Emerson Industrial, Danbury, CT, USA) during each extraction, until the final pellet was colorless. Then, supernatants were pooled and centrifuged at $1419 g$ during 10 min at $4{ }^{\circ} \mathrm{C}$ and chlorophyll (Chl) $a+b$ content and the Chl $a / b$ ratio were determined spectrophotometrically using the equations described by Lichtenthaler (1987).

\section{Lipid peroxidation analyses}

Lipid peroxidation levels were determined by analyzing primary (lipid hydroperoxide) and secondary (malondialdehyde, MDA) lipid peroxidation products. First, for evaluating lipid hydroperoxides content, frozen samples were extracted with methanol containing $0.01 \%$ BHT (w/v) at $4{ }^{\circ} \mathrm{C}$ using 30 min of ultra-sonication (Bransonic ultrasonic bath 2800) and centrifugation at $1419 \mathrm{~g}$ for $10 \mathrm{~min}$ at $4{ }^{\circ} \mathrm{C}$. Then, two re-extractions were performed. Supernatants were pooled and used for analyses using the Fox-2 reagent (consisting in a solution of $90 \%$ methanol (v/v) containing $25 \mathrm{mM}$ sulfuric acid, $4 \mathrm{mM}$ BHT, $0.25 \mathrm{mM}$ iron sulfate ammonium (II) and $0.1 \mathrm{mM}$ xylenol orange) as described in Bou et al. (2008). Absorbances were measured at 560 and $800 \mathrm{~nm}$. A calibration curve using hydrogen peroxide $37 \%(\mathrm{v} / \mathrm{v})$ was used for quantification.

For determining the MDA content, the thiobarbituric acid-reactive substances assay, was used as in Hodges et al. (1999). In brief, samples were extracted with $80 \%$ (v/v) ethanol containing $0.01 \%(\mathrm{w} / \mathrm{v}) \mathrm{BHT}$, then vortexed for $20 \mathrm{~s}$ and exposed to ultrasonication for $30 \mathrm{~min}$ (Bransonic ultrasonic bath 2800). After a centrifugation process at room temperature for $13 \mathrm{~min}$ at $1091 \mathrm{~g}$, the supernatant was recovered, and the pellet re-extracted twice using the same procedure. Then, two tubes for sample were used: (i) - thiobarbituric acid (TBA), with $1 \mathrm{~mL}$ extract $+1 \mathrm{~mL} 20 \%$ trichloroacetic acid (w/v) with $0.01 \%$ BHT (w/v) and (ii) + TBA, with $1 \mathrm{~mL}$ extract $+1 \mathrm{~mL} 20 \%$ trichloroacetic acid (w/v), $0.01 \%$ BHT (w/v) and $0.65 \%$ TBA (w/v). Tubes were incubated at $95{ }^{\circ} \mathrm{C}$ for $25 \mathrm{~min}$. Subsequently, the reaction was stopped by maintaining them at $4{ }^{\circ} \mathrm{C}$ for $10 \mathrm{~min}$. After centrifugation at $1091 \mathrm{~g}$ at room temperature for $5 \mathrm{~min}$, MDA content in samples were analyzed by spectrophotometry and quantified using the equations developed by Hodges et al. (1999).

\section{Vitamin E analyses}

The quantification of the different homologues of tocopherols and tocotrienols $(\alpha, \beta, \gamma$ and $\delta)$ was performed as follows. Samples were extracted with methanol containing $0.01 \%$ BHT (w/v). Samples were extracted and re-extracted twice using vortex for $20 \mathrm{~s}$ followed by $30 \mathrm{~min}$ of ultrasonication (Bransonic ultrasonic bath 2800). Then, supernatants were pooled and centrifuged at $1419 \mathrm{~g}$ during $10 \mathrm{~min}$ at $4{ }^{\circ} \mathrm{C}$ before passing them onto a hydrophobic PTFE filter $0.22 \mu \mathrm{m}$ (Phenomenex, Torrance, CA, USA) and introducing them into vials. Vitamin E compounds were separated by HPLC at room temperature using an Inertsil 100A column $(5 \mu \mathrm{m}$, $0.03 \times 0.25 \mathrm{~m}$, GL Sciences Inc., Tokyo, Japan) and quantified with a fluorescent detector, as described by Amaral et al. (2005). A calibration curve was made with authentic standards (Sigma-Aldrich, Steinheim, Germany) for each of the tocopherols and tocotrienols analyzed.

\section{Statistical analyses}

Statistical analyses were performed by applying a one-way ANOVA and indicating Duncan post hoc differences with different letters among different times of measurements (IBS SPSS Statistics 19; SPSS Inc., IL, USA). Differences were considered significant when $P$ values were below 0.05 $(P<0.05)$. 

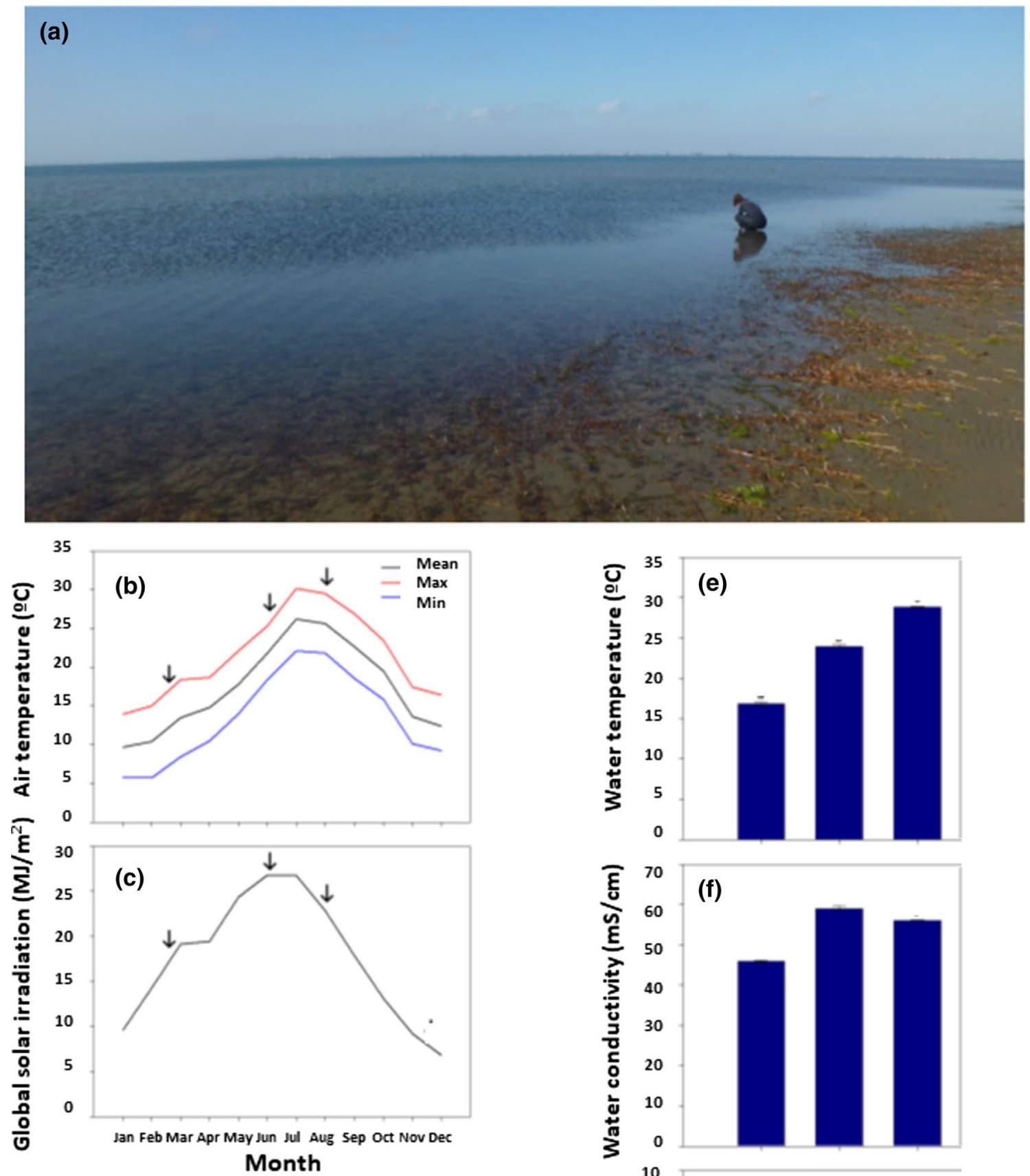

(d)
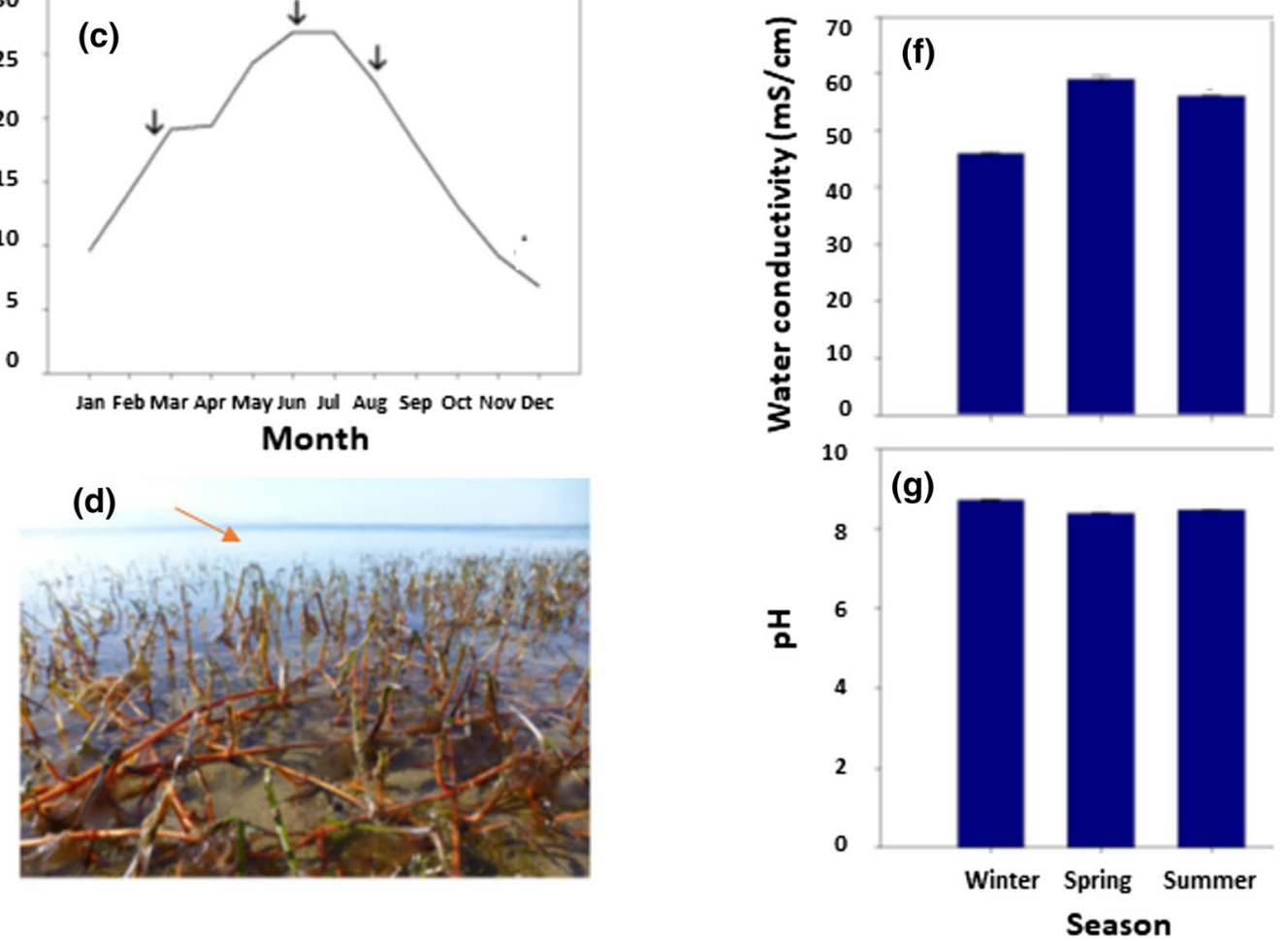
4Fig. 1 Environmental and site characteristics of the natural ecosystem of the Alfacs Bay where $C$. nodosa was studied. a Photograph of the study site. b, c Mean monthly air temperature and global solar radiation in the Alfacs Bay during the year of the study. d Experimental site where $C$. nodosa plants were collected for the study. $\mathbf{e}-\mathbf{g}$ Water temperature, conductivity and $\mathrm{pH}$ during the samplings performed in winter, spring and summer. Data are the mean SE of $n=5$

\section{Results}

\section{Cold stress causes desiccation during winter stress in leaves, but not in rhizomes}

Cymodocea nodosa plants collected from shallow areas at $2 \mathrm{~m}$ depth in the Ebro delta (Fig. 1a) were subjected to contrasting environmental conditions during the year. This area was characterized by minimum and maximum monthly air temperatures of $5{ }^{\circ} \mathrm{C}$ and $30^{\circ} \mathrm{C}$ during winter and summer, respectively (Fig. 1b), periods that coincided with relatively low and very high global solar irradiation received during the year (Fig. 1c). During the sampling of winter (February 25, 2019), which was performed at midday, plants were under water at $2 \mathrm{~m}$ depth (at about $100 \mathrm{~m}$ from the coastline, Fig. 1d) and exposed to a water temperature of $15.3{ }^{\circ} \mathrm{C}$ (Fig. 1e), conductivity of $50 \mathrm{mS} /$ $\mathrm{cm}$ (Fig. 1f) and pH of 8.5 (Fig. 1g). During the next samplings of spring and summer, air and water temperature increased progressively (Fig. 1b, e), global solar irradiation attained its maximum yearly values (Fig. 1c) and water conductivity was 20-30\% higher (Fig. 1f), whereas $\mathrm{pH}$ was only very slightly lower, with values always above 8 (Fig. 1e). In other words, plants were subject to changing physical variables, but water temperature was most altered during the two sampling extremes since it doubled from winter to summer (Fig. 1e). Tissue hydration measurements revealed that cold stress during winter caused leaf but not rhizome desiccation. Hydration, with values of 3.2 and $4 \mathrm{~g} \mathrm{H}_{2} \mathrm{O} / \mathrm{g}$ dry matter in leaves and rhizomes, respectively, recovered during spring and summer in leaves, but remained constant in rhizomes during the same period (Fig. 2a, b). Cold-induced desiccation was confirmed by exposing winter leaves (Fig. 2c) and rhizomes (Fig. 2d) to a water temperature of $8{ }^{\circ} \mathrm{C}$ under laboratory conditions (by exposing plants to cold stress in a cold chamber for 3 days in seawater). In this experiment, it was observed that hydration decreased progressively during cold stress in leaves (particularly after one day of cold stress exposure, Fig. 2e), while rhizomes kept their water contents (Fig. 2f). To sum up, leaves of C. nodosa plants in the Ebro delta were exposed to cold stress during winter, an abiotic factor that induced leaf desiccation as well, while the same environmental conditions did not induce desiccation of rhizomes (the perennial organ).

\section{Chlorophyll loss, photo-inhibition and vitamin E during winter stress}

Chls contents in leaves during winter averaged $3.95 \mathrm{mg} / \mathrm{g}$ dry matter, and they increased progressively during spring and summer to attain values up to $8.50 \mathrm{mg} / \mathrm{g}$ dry matter, that is more than twofold higher in summer compared to winter (Fig. 3a). Seasonal variations also revealed higher $\mathrm{Chl} a / b$ and lower $F_{\mathrm{v}} / F_{\mathrm{m}}$ values during winter compared to summer, with Chl $a / b$ values decreasing from 2.5 to $2.1 \mathrm{~g} / \mathrm{g}$ and $F_{\mathrm{v}} / F_{\mathrm{m}}$ ratios increasing from 0.59 to 0.78 from winter to summer, respectively (Fig. 3b, c). It noteworthy that $F_{\mathrm{v}} / F_{\mathrm{m}}$ values averaged values below 0.75 , which is the threshold indicating photoinhibition (see Takahashi and Badger 2011), both during winter and spring (Fig. 3c), paralleling variations in leaf hydration (Fig. 2a) and water temperature (Fig. 1e).

Vitamin E analyses revealed that $C$. nodosa leaves contained tocopherols, but not tocotrienols, and the major tocopherol was in the form of $\alpha$-tocopherol ( $\alpha$-toc), which was found at a concentration of $290 \mu \mathrm{g} / \mathrm{g}$ dry matter in winter (Fig. 3d). $\gamma$-Tocopherol was found in some samples only, and when present it was always present at very low, not quantifiable amounts (traces). $\beta$ - and $\delta$-tocopherols and all tocotrienols were not detected in any sample (detection limit $<1 \mu \mathrm{g} / \mathrm{g}$ dry matter). Therefore, $\alpha$-toc accounted always above $99 \%$ of the total vitamin $\mathrm{E}$ content. While $F_{\mathrm{v}} / F_{\mathrm{m}}$ ratio increased progressively between winter and summer (Fig. 2c), $\alpha$-toc content followed a different trend keeping higher both during winter and spring compared to summer (Fig. 3d). In contrast, the $\alpha$-toc content expressed on a Chl basis did vary similarly to the $\mathrm{Chl} a / b$ ratio (Fig. $3 b$ ) and inversely to the $F_{\mathrm{v}} / F_{\mathrm{m}}$ ratio (Fig. $3 \mathrm{c}$ ), with the maximum $\alpha$-toc/Chl ratios attained during winter $(0.079 \mathrm{~g} / \mathrm{g} \mathrm{Chl}$, which is equivalent to $79 \mathrm{mg} / \mathrm{g} \mathrm{Chl}$, Fig. 3e). Noteworthy, the maximum $\alpha$-toc/ $\mathrm{Chl}$ ratios coincided with the lowest contents of primary (LOOH) and secondary (MDA) lipid peroxidation products during winter (Fig. 4a, b). Despite the LOOH/MDA ratio kept constant during the study (Fig. 4c), LOOH and MDA contents were much lower during winter than during spring and summer (Fig. 4a, b).

\section{Vitamin E and lipid peroxidation in rhizomes}

The extent of lipid peroxidation in rhizomes was in general lower compared to leaves, at least in terms of $\mathrm{LOOH}$ and MDA accumulation, and it also followed a completely different trend. $\mathrm{LOOH}$ content in rhizomes peaked at winter, with values reaching $38 \mathrm{nmol} / \mathrm{g}$ dry matter (Fig. 5a). MDA content in rhizomes was constant over the seasons and kept very low, always with mean values below $5 \mathrm{nmol} / \mathrm{g}$ dry matter (Fig. 5b). The MDA/LOOH ratio in rhizomes also kept at constant levels between samplings (Fig. 5c), as it occurred in leaves (Fig. 4c), but always at levels $90 \%$ lower 

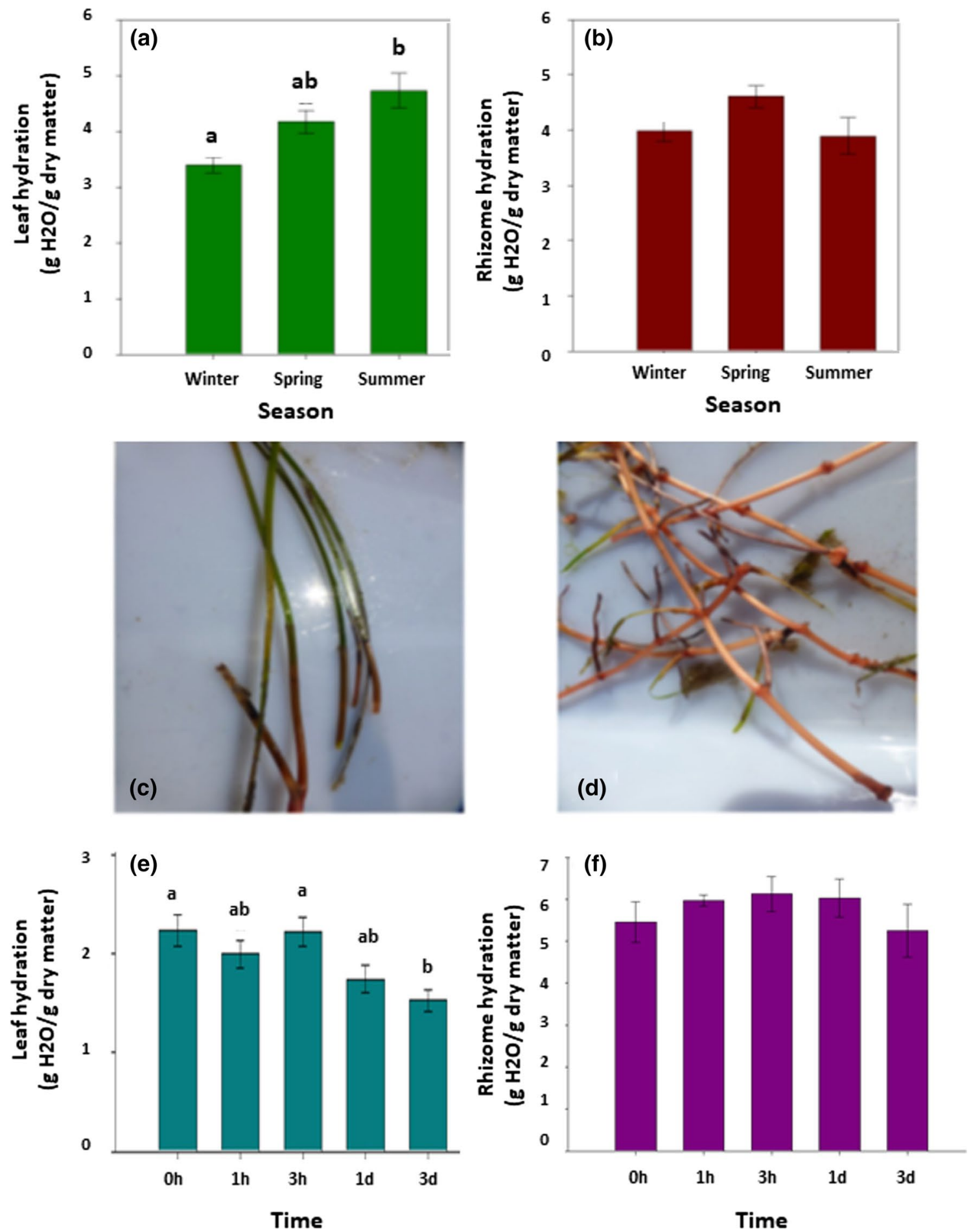

Fig. 2 Water content of $C$. nodosa plants. a, b Seasonal variations in leaf and rhizome hydration in Alfacs Bay. $\mathbf{c}$, d Detail of leaves and rhizomes used in the study of water loss under controlled conditions. e, f Dynamics of leaf and rhizome hydration during exposure to $8{ }^{\circ} \mathrm{C}$

in a cold chamber. Data are the mean SE of $n=15$ for the natural site and $n=5$ for controlled conditions. Different letters indicate statistical differences between sampling time points (Duncan post hoc tests, one-way ANOVA, $P<0.05$ ) 

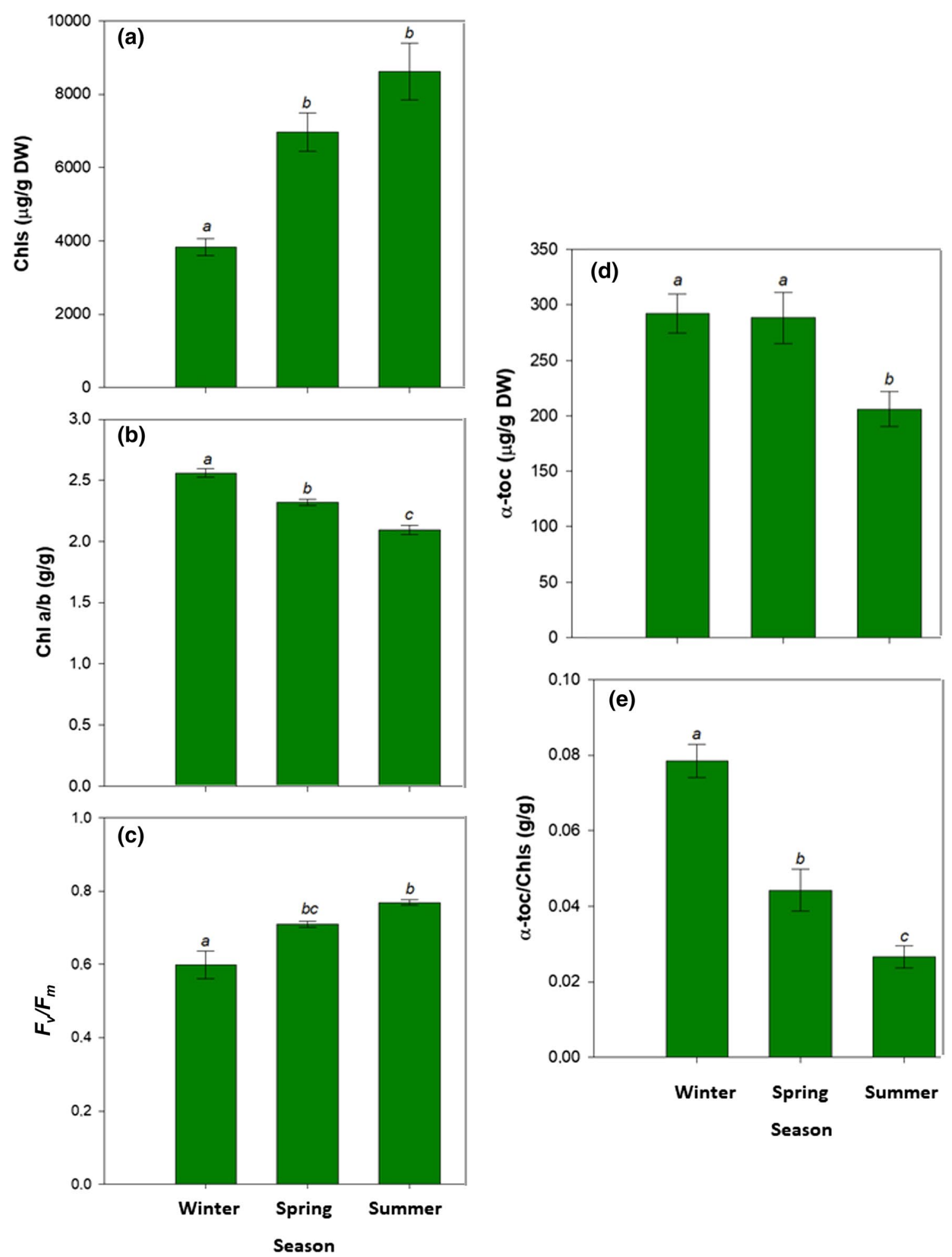

Fig. 3 Seasonal variations in chlorophyll contents, photoinhibition and vitamin $\mathrm{E}$ contents in leaves of $C$. nodosa. a Chlorophyll $a+b$ (Chls) content, b Chl $a / b$ ratio, $\mathbf{c}$ maximum efficiency of PSII photochemistry, $\mathbf{d} \alpha$-tocopherol ( $\alpha$-toc) content and $\mathbf{e} \alpha$-toc/Chls ratio of

leaves of $C$. nodosa plants in the Alfacs Bay during winter, spring and summer. Data are the mean SE of $n=15$. Different letters indicate statistical differences between sampling time points (Duncan post hoc tests, one-way ANOVA, $P<0.05$ ) 

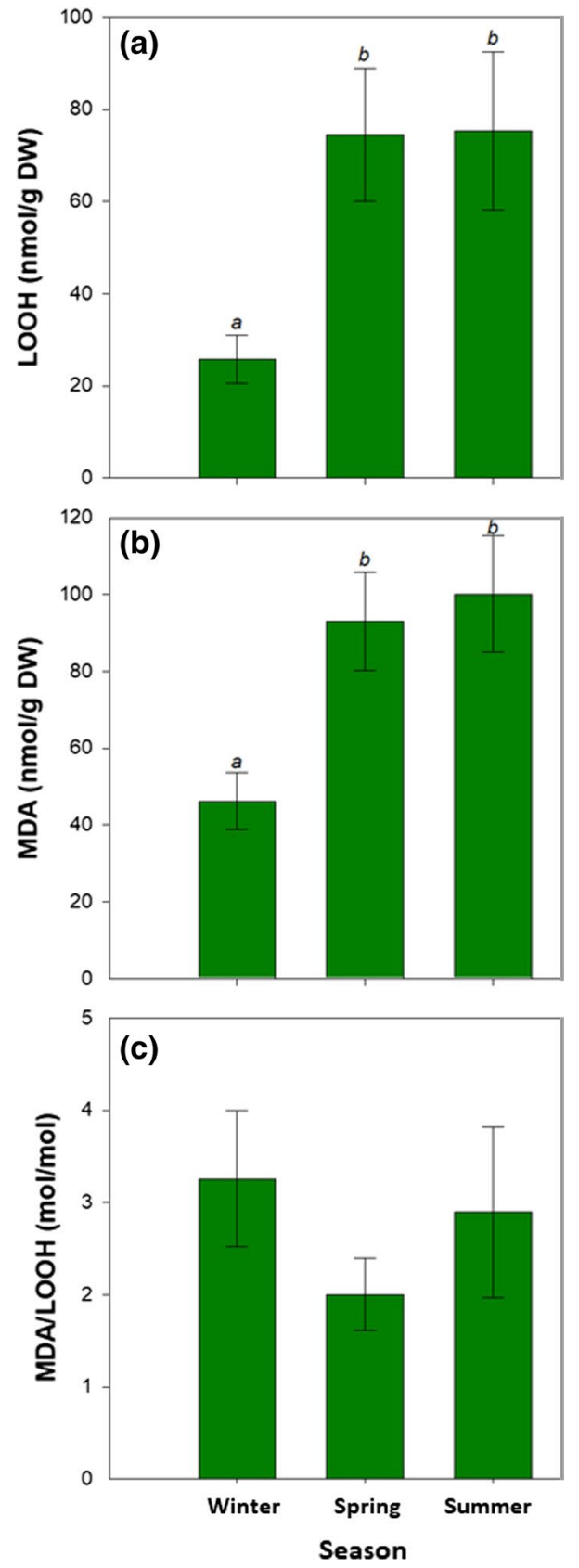

Fig. 4 Seasonal variations in the extent of lipid peroxidation in leaves of $C$. nodosa. a Contents of lipid hydroperoxides ( $\mathrm{LOOH})$, a primary lipid peroxidation product, b malondialdehyde (MDA), a secondary product of lipid peroxidation, and $\mathbf{c}$ LOOH/MDA ratio in leaves of $C$. nodosa plants in the Alfacs Bay during winter, spring and summer. Data are the mean SE of $n=15$. Different letters indicate statistical differences between sampling time points (Duncan post hoc tests, one-way ANOVA, $P<0.05$ )

than in leaves. Vitamin E contents in rhizomes, also represented by more than $99 \%$ of $\alpha$-toc, were also much lower than in leaves, with $\alpha$-toc contents being slightly higher in winter and spring, compared to summer (Fig. 5d). It is noteworthy that the scavenging activity of $\alpha$-toc against lipid peroxyl radicals to prevent the propagation of lipid peroxidation in thylakoid membranes prevents MDA production, but this activity itself leads to $\mathrm{LOOH}$ production (Fig. 5e, see also Muñoz and Munné-Bosch 2019).

\section{Discussion}

The five species of marine angiosperms that inhabit the Western Mediterranean are Posidonia oceanica, Cymodocea nodosa, Zostera marina, Zostera noltii and Ruppia cirrhosa (Romero et al. 2015). Most of the populations of $C$. nodosa are distributed from along the Spanish coasts of the Mediterranean, but they can also be found along the Atlantic coasts of southern Portugal and the northeast Africa (Pérez et al. 2015). Being the second marine angiosperm of greater extension of the Spanish coasts after $P$. oceanica (Ruiz et al. 2015), C. nodosa is a species of warm water that lives in sand or mud bottoms of shallow areas (Boudouresque et al. 2009), although it can also be present in less dense populations in deeper waters (Romero et al. 2015). Depending on the geographical area, it can reach a maximum depth that varies between 15 and $36 \mathrm{~m}$ (Pérez et al. 2015). The populations that are in shallow areas, due to the high intensity of the sea current, are usually more discontinuous populations, unlike what is observed in the populations of greater depth, and phenotypic plasticity provides them tolerance to a wide range of environmental conditions (Pérez et al. 2015). This allows C. nodosa to grow in areas where temperature and salinity conditions can reach extreme values (Pérez et al. 2015). For example, populations have been mapped in Alfacs Bay, where minimum and maximum temperatures can reach $7{ }^{\circ} \mathrm{C}$ and $30^{\circ} \mathrm{C}$, respectively (Romero et al. 2015). In addition, it has been shown that this species can tolerate a wide range of salinity levels (Pérez et al. 2015), as well as seasonal variations that cause changes in light, temperature, and conditions of nutrient discharge (Marbà et al. 1996; Guidetti et al. 2002; Bracun 2016). C. nodosa has a great ability to colonize new areas in a short time due to the huge capacity of the rhizome for rapid growth, except in the winter months when this growth capacity is reduced (Duarte et al. 2006). Here, it is shown that the rhizome has a greater capacity than leaves to tolerate low-temperature stress, being the rhizome more desiccation tolerant than leaves and showing a lower extent of lipid peroxidation, as indicated by lower MDA contents.

Some studies in $C$. nodosa suggest that its optimal growth temperature may oscillate between $24.5{ }^{\circ} \mathrm{C}$ (Peduzzi and Vukovic 1990; Lee et al. 2007) and $30-32{ }^{\circ} \mathrm{C}$ (Terrados and Ros 1995). Therefore, our study is in agreement with these previous results in relation to the temperatures at which $C$. nodosa suffers from photo-inhibition 
(both during autumn and winter, but particularly during the latter), and it further supports the contention that C. nodosa is very well adapted to warm temperatures. Low temperatures in plants can generate various types of stresses, including desiccation and osmotic stress, as well as oxidative stress, most particularly when combined with high solar radiation. Despite growing in waters with seasonal variations in light attenuation coefficients, plants received irradiances in excess of $1000 \mu \mathrm{mol} \mathrm{m}^{-2} \mathrm{~s}^{-1}$ of photosynthetically active photon flux density at noon in winter, spring and summer, well above the levels necessary to saturate photosynthesis, as previously shown in laboratory experiments (90-400 $\mu \mathrm{mol} \mathrm{m}^{-2} \mathrm{~s}^{-1}$; Pérez and Romero 1992). In the present study, we showed that low temperatures induced desiccation in leaves, but not in rhizomes, and that both leaves and rhizomes were very tolerant to cold-induced oxidative stress. Although rhizomes experienced increased oxidative stress during winter, as indicated by enhanced $\mathrm{LOOH}$ contents during winter compared to autumn and spring, MDA contents did not increase, thus indicating absence of oxidative damage. Furthermore, it appeared that, despite the transient photoinhibition occurring in leaves during winter, an increased $\alpha$-toc/Chl ratio led to an enhanced protection of the photosynthetic apparatus. The $\alpha-\mathrm{Toc} / \mathrm{Chl}$ ratio increased during winter mostly because of a reduction of Chl levels, thus indicating that $\mathrm{Chl}$ degradation at low temperatures may improve the antioxidant capacity of leaves per amount of photons absorbed, as it occurs in terrestrial plants (Kyparissis et al. 2000; Munné-Bosch and Alegre 2000; Fernández-Marín et al. 2017; Baccari et al. 2020). Interestingly, this is another ecological case study in which chlorophyll loss combined with enhanced antioxidant protection per amount of photons absorbed is associated with transient photoinhibition and full recovery from stress, in this case, low-temperature stress combined with relatively high solar radiation during winter in a seagrass, a model that was not investigated in this respect thus far. It is noteworthy that the $F_{\mathrm{v}} / F_{\mathrm{m}}$ ratio strongly negatively correlated with the $\alpha$-toc/Chl ratio and the Chl $a / b$ ratio, but not with markers of the extent of lipid peroxidation (Fig. 6a, b). Thus, adjustments in the pigment antenna size, consisting of a reduction of chlorophyll contents, but most particularly of $\mathrm{Chl} b$, might help provide enhanced antioxidant protection, in terms of $\alpha$-toc relative to the amount of photons absorbed in the antenna, thus leading to an overprotection from potential singlet oxygen damage in PSII (Fig. 6c, d). At this point, it is very difficult to discern whether the increase in the $\alpha$-toc/Chl ratio led to reduced photo-inhibition, or if the occurrence of photo-inhibition caused an increased $\alpha$-toc/ $\mathrm{Chl}$ ratio, since it is known that singlet oxygen produces photo-inhibition, but also that $\alpha$-toc could protect PSII from sustained photo-inhibitory damage (Kumar et al. 2021). One outlier showing $F_{\mathrm{v}} / F_{\mathrm{m}}$ values below 0.15 suggests that strong photo-inhibition may occur because of the inability of leaves to rapidly reduce $\mathrm{Chl} b$ levels that consequently lead to the absence of sufficiently increased $\alpha$-toc/Chl ratio (Fig. 6b). However, further studies are necessary to study inter-clonal differences in photoinhibition, photo-oxidative stress and photoinhibitory damage in $C$. nodosa plants. It should be noted that these plants make new leaves constantly, most particularly during summer months, and they grow and colonize new space during each spring and summer making new clones (Pérez et al. 1994; Cancemi et al. 2002), which together with the fact that they adapt well to their environment, even to the cold temperatures experienced during winter, as shown in the present study, it is suggested that anthropogenic factors rather than environmental ones are the major risk these meadows are facing nowadays in a frame of global change.

In conclusion, our results indicate that (i) adjustments in pigment antenna size and vitamin $\mathrm{E}$ contents per unit of Chl during winter may help protect the photosynthetic apparatus from sustained photoinhibitory damage and lipid peroxidation events in leaves of $C$. nodosa, (ii) rhizomes also accumulate large amounts of vitamin $\mathrm{E}$, although to a much lesser extent than leaves, and keep protected from lipid peroxidation during winter, as indicated by malondialdehyde contents, and (iii) vitamin E can help protect both leaves and rhizomes from lipid peroxidation in marine angiosperms, as it occurs in terrestrial plants, although cold stress during winter can cause transient photoinhibition of the photosynthetic apparatus in $C$. nodosa. 

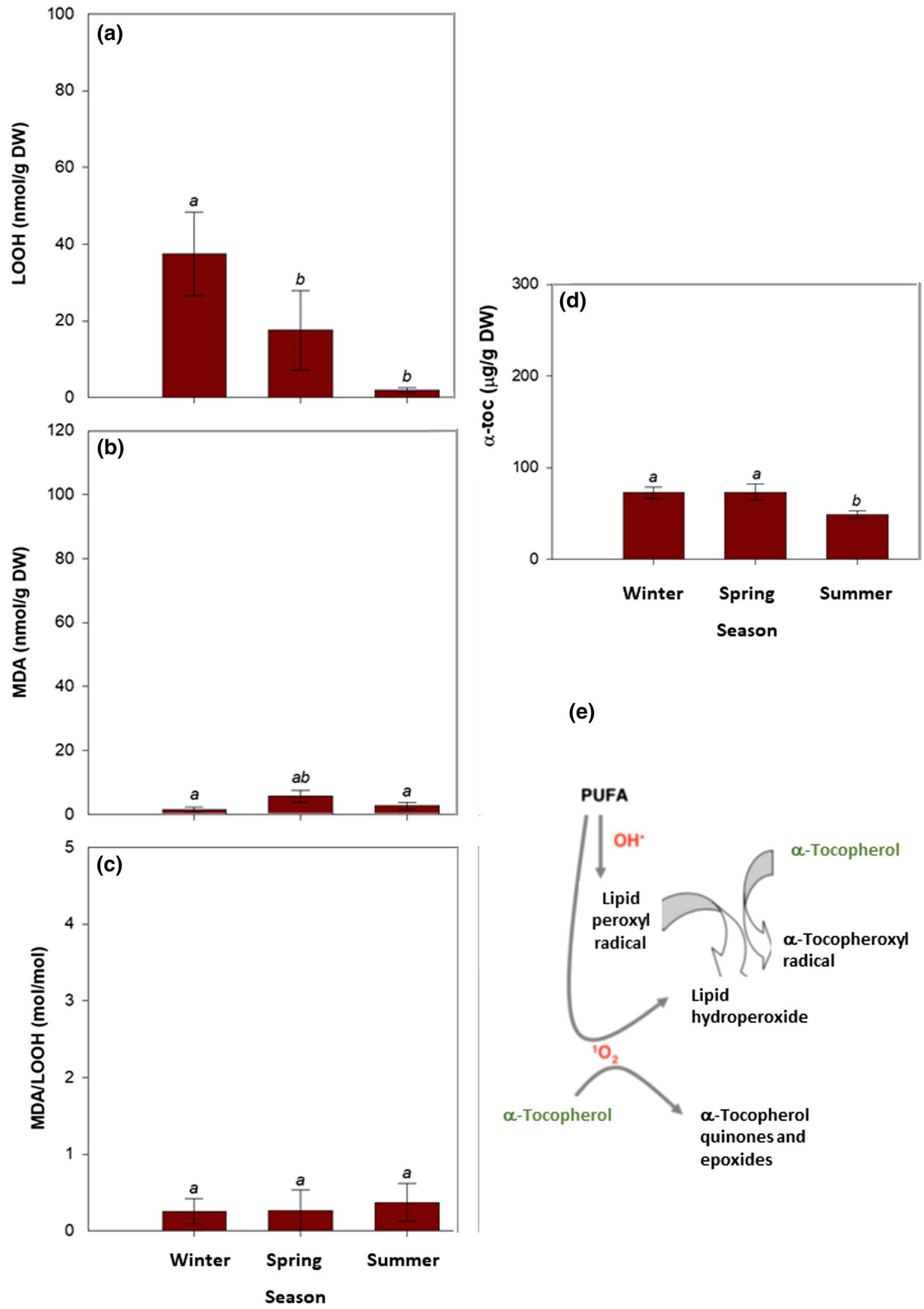
4 Fig. 5 Seasonal variations in the extent of lipid peroxidation and vitamin E content in rhizomes of $C$. nodosa in the Alfacs Bay during winter, spring and summer. a Contents of lipid hydroperoxides (LOOH), a primary lipid peroxidation product, b malondialdehyde (MDA), a secondary product of lipid peroxidation, $\mathbf{c}$ LOOH/MDA ratio, and $\mathbf{d} \alpha$-tocopherol ( $\alpha$-toc). $\mathbf{e}$ Antioxidant function of $\alpha$-toc as a chain-breaking antioxidant reacting with lipid peroxyl radicals and hence inhibiting the propagation of lipid peroxidation. Note that this reaction gives rise to the production of $\mathrm{LOOH}$. Data are the mean $\mathrm{SE}$ of $n=15$. Different letters indicate statistical differences between sampling time points (Duncan post hoc tests, one-way ANOVA, $P<0.05)$

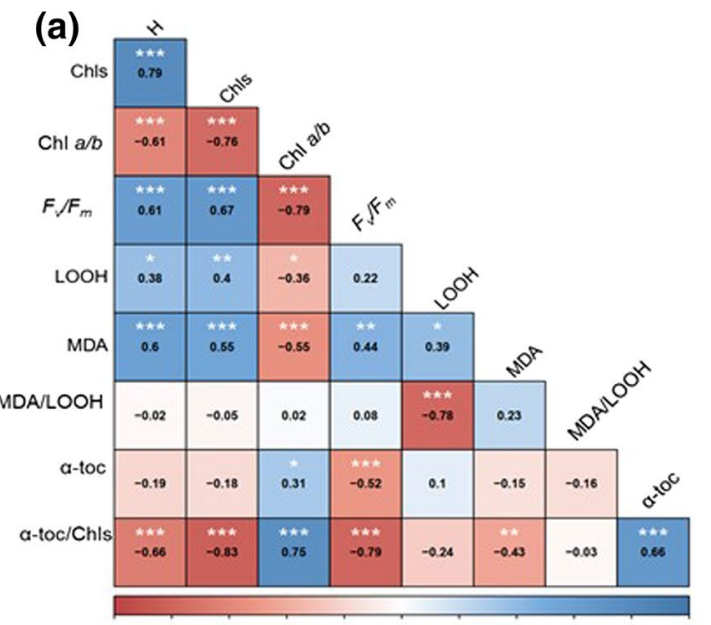

(b)

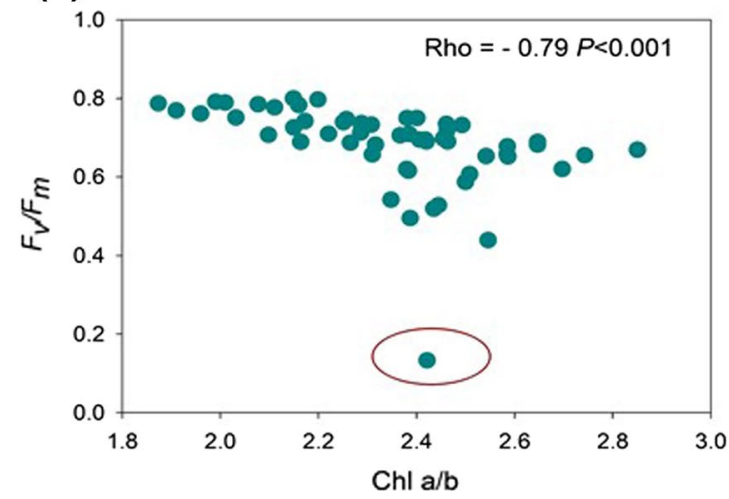

Fig. 6 Correlations and model depicting of action of vitamin $\mathrm{E}$ in the protection of $C$. nodosa leaves from winter stress. a Spearman's rank correlation analyses between the measured parameters in $C$. nodosa (c)
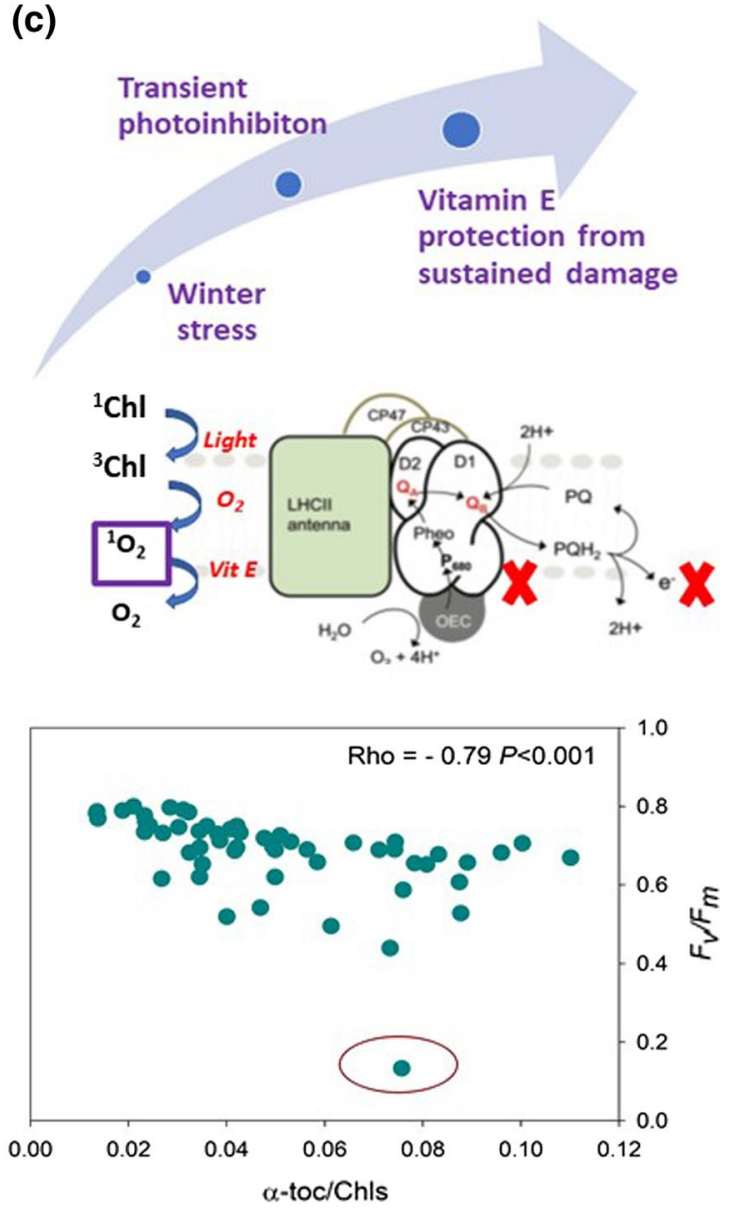

leaves. b Example of the strongest correlations observed with the $F_{\mathrm{v}} / F_{\mathrm{m}}$ ratio. c Model explaining the possible role of vitamin $\mathrm{E}$ at the molecular level in photosynthetic membranes of $C$. nodosa 
Author contribution statement SMB conceived of the project with the help of SP. SP performed samplings with the help of ERF. AC and ESF performed biochemical analyses. SMB and ESF analyzed and interpreted the results and wrote the manuscript. All authors revised and approved the manuscript.

\begin{abstract}
Acknowledgements We are very grateful to the Serveis Científicotècnics from the University of Barcelona for technical assistance. We thank Sandra Rasero for her help with biochemical analyses. We are also indebted to the Generalitat de Catalunya for the ICREA Academia prize given to SMB and the support received with the 2017 SGR 980 grant.
\end{abstract}

Funding Open Access funding provided thanks to the CRUE-CSIC agreement with Springer Nature.

Data availability All of the raw data will be made available on reasonable request to the corresponding author.

Open Access This article is licensed under a Creative Commons Attribution 4.0 International License, which permits use, sharing, adaptation, distribution and reproduction in any medium or format, as long as you give appropriate credit to the original author(s) and the source, provide a link to the Creative Commons licence, and indicate if changes were made. The images or other third party material in this article are included in the article's Creative Commons licence, unless indicated otherwise in a credit line to the material. If material is not included in the article's Creative Commons licence and your intended use is not permitted by statutory regulation or exceeds the permitted use, you will need to obtain permission directly from the copyright holder. To view a copy of this licence, visit http://creativecommons.org/licenses/by/4.0/.

\section{References}

Amaral JS, Casal S, Torres D, Seabra RM, Oliveira BPP (2005) Simultaneous determination of tocopherols and tocotrienols in hazelnuts by a normal phase liquid chromatographic method. Anal Sci $21: 1545-1548$

Asada K (2006) Production and scavenging of reactive oxygen species in chloroplasts and their functions. Plant Physiol 141:391-396

Baccari S, Elloumi O, Chaari-Rkhis A, Fenollosa E, Morales M, Drira N, Ben Abdallah F, Fki L, Munné-Bosch S (2020) Linking leaf water potential, photosynthesis and chlorophyll loss with mechanisms of photo- and antioxidant protection in juvenile olive trees subjected to severe drought. Front Plant Sci 11:614144

Banerjee K, Paneerselvam A, Ramachandran P, Ganguly D, Singh G, Ramesh R (2018) Seagrass and macrophyte mediated $\mathrm{CO}_{2}$ and $\mathrm{CH}_{4}$ dynamics in shallow coastal waters. PLoS One 13:e0203922

Barbier EB, Hacker SD, Kennedy C, Koch EW, Stier AC, Silliman BR (2011) The value of estuarine and coastal ecosystem services. Ecol Monogr 81:169-193

Bou R, Codony R, Tres A, Decker EA, Guardiola F (2008) Determination of hydroperoxides in foods and biological samples by the ferrous oxidation-xylenol orange method: a review of the factors that influence the method's performance. Anal Biochem 377:1-15

Boudouresque CF, Bernard G, Pergent G, Shili A, Verlaque M (2009) Regression of Mediterranean seagrasses caused by natural processes and anthropogenic disturbances and stress: a critical review. Bot Mar 52:395-418

Bracun S (2016) Seasonal growth patterns of Cymodocea nodosa and abundance patterns of its epiphytes in relation to depth in the Northern Adriatic Sea. Karl-Franzens-Universität Graz University of Graz, Graz

Cancemi G, Buia MC, Mazzella L (2002) Photosynthetic response to light and temperature of the seagrass Cymodocea nodosa and the prediction of its seasonality. Sci Mar 66:365-373

Duarte CM, Fourqurean JW, Krause-Jensen D, Olesen B (2006) Dynamics of seagrass stability and change. In: Larkum AWD, Orth RJ, Duarte CM (eds) Seagrasses: biology, ecology and conservation. Springer, Dordrecht, pp 271-294

Falk J, Munné-Bosch S (2010) Tocochromanol functions in plants: antioxidation and beyond. J Exp Bot 61:1549-1566

Fernández-Marín B, Hernández A, Garcia-Plazaola JI, Esteban R, Míguez F, Artetxe U, Gómez-Sagasti MT (2017) Photoprotective strategies of Mediterranean plants in relation to morphological traits and natural environmental pressure: a meta-analytical approach. Front Plant Sci 8:1051

Guidetti P, Lorenti M, Buia MC, Mazzella L (2002) Temporal dynamics and biomass partitioning in three Adriatic seagrass species: Posidonia oceanica, Cymodocea nodosa, Zostera marina. Mar Ecol 23:51-67

Hasanuzzaman M, Bhuyan MHMB, Zulfiqar F, Raza A, Mohsin SM, Mahmud JA, Fujita M, Fotopoulos V (2020) Reactive oxygen species and antioxidant defense in plants under abiotic stress: revisiting the crucial role of a universal defense regulator. Antioxidants 9:681

Havaux M, Eymery F, Profirova S, Rey P, Dörmann P (2005) Vitamin E protects against photoinhibition and photooxidative stress in Arabidopsis thaliana. Plant Cell 17:3451-3469

Hemminga MA, Duarte CM (2000) Seagrass ecology. Cambridge University Press, Cambridge

Hodges DM, DeLong JM, Forney CF, Prange RK (1999) Improving the thiobarbituric acid-reactive-substances assay for estimating lipid peroxidation in plant tissues containing anthocyanin and other interfering compounds. Planta 207:604-611

Inoue S, Ejima K, Iwai E, Hayashi H, Appel J, Tyystjärvi E, Murata N, Nishiyama Y (2011) Protection by $\alpha$-tocopherol of the repair of photosystem II during photoinhibition in Synechocystis sp. PCC 6803. Biochim Biophys Acta 1807:236-241

Kanwischer M, Porfirova S, Bergmüller E, Dörmann P (2005) Alterations in tocopherol cyclase activity in transgenic and mutant plants of Arabidopsis affect tocopherol content, tocopherol composition, and oxidative stress. Plant Physiol 137:713-723

Krieger-Liszkay A, Trebst A (2006) Tocopherol is the scavenger of singlet oxygen produced by the triplet states of chlorophyll in the PSII reaction centre. J Exp Bot 57:1677-1684

Kumar A, Prasad A, Sedlářová M, Kale R, Frankel LK, Sallans L, Bricker TM, Pospíšil P (2021) Tocopherol controls D1 amino acid oxidation by oxygen radicals in photosystem II. Proc Natl Acad Sci USA 118:e2019246118

Kyparissis A, Drilias P, Manetas Y (2000) Seasonal fluctuations in photoprotective (xanthophyll cycle) and photoselective (chlorophylls) capacity in eight Mediterranean plant species belonging to two different growth forms. Aust J Plant Physiol 27:267-274

Lee K-S, Park SR, Kim YK (2007) Effects of irradiance, temperature, and nutrients on growth dynamics of seagrasses: a review. J Exp Mar Biol Ecol 350:144-175

Lichtenthaler HK (1987) Chlorophylls and carotenoids: pigments of photosynthetic biomembranes. Methods Enzymol 148:350-382

Marbà N, Cebrian J, Enriquez S, Duarte CM (1996) Growth paterns of Western Mediterranean seagrasses: species-specific responses to seasonal forcing. Mar Ecol Progr Ser 133:203-215 
Munné-Bosch S, Alegre L (2000) Changes in carotenoids, tocopherols and diterpenes during drought and recovery, and the biological significance of chlorophyll loss in Rosmarinus officinalis plants. Planta 210:925-931

Munné-Bosch S, Alegre L (2002) Interplay between ascorbic acid and lipophilic antioxidant defences in chloroplasts of water-stressed Arabidopsis plants. FEBS Lett 524:145-148

Muñoz P, Munné-Bosch S (2019) Vitamin E in plants: biosynthesis, transport, and function. Trends Plant Sci 24:1040-1051

Orth RJ, Carruthers TJB, Dennison WC, Duarte CM, Fourqurean JW, Heck KL, Randall Hughes A, Kendrick GA, Judson Kenworthy W, Olyarnik S, Short FT, Waycott M, Williams SL (2006) A global crisis for seagrass ecosystems. Bioscience 56:987-996

Peduzzi P, Vukovic A (1990) Primary production of Cymodocea nodosa in the Gulf of Trieste (Northern Adriatic Sea): a comparison of methods. Mar Ecol Prog Ser 64:197-207

Pérez M, Romero J (1992) Photosynthetic response to light and temperature of the seagrass Cymodocea nodosa and the prediction of its seasonality. Aquat Bot 43:51-62

Pérez M, Duarte CM, Romero J, Sand-Jensen K, Alcoverro T (1994) Growth plasticity in Cymodocea nodosa stands: the importance of nutrient supply. Aquat Bot 47:249-264

Pérez M, Díaz E, Ruiz JM (2015) Las praderas marinas de España: una visión general. In: Ruiz JM, Guillén JE, Ramos-Segura A, Otero MM (eds) Atlas de las praderas marinas de España. Instituto de Ecología Litoral/UICN, Alicante, pp 37-53

Romero J, Pérez M, Alcoverro T, Torres M, Manzanera M, Allué R (2015) Praderas de angiospermas marinas: Cataluña. Atlas de las praderas marinas de España. In: Ruiz JM, Guillén JE, Ramos-Segura A, Otero MM (eds) Atlas de las praderas marinas de España. Instituto de Ecología Litoral/UICN, Alicante, pp 121-178

Ruiz JM, Ramos A, Tello O (2015) Las praderas marinas de España: una visión general. Ecología y extensión de las praderas marinas. In: Ruiz JM, Guillén JE, Ramos-Segura A, Otero MM (eds) Atlas de las praderas marinas de España. Instituto de Ecología Litoral/ UICN, Alicante, pp 54-73

Takahashi S, Badger MR (2011) Photoprotection in plants: a new light on photosystem II damage. Trends Plant Sci 16:53-60

Terrados J, Ros JD (1995) Temperature effects on photosynthesis and depth distribution of the seagrass Cymodocea nodosa (Ucria) Ascherson in a Mediterranean coastal lagoon: the Mar Menor (SE Spain). Mar Ecol 16:133-144

Trebst A (2003) Function of beta-carotene and tocopherol in photosystem II. Z Naturforsch C 58:609-620

Van der Heide T, Govers LL, de Fouw J, Olff H, Van der Geest M, Van Katwijk MM, Piersma T, Van de Koppel J, Silliman BR, Smolders AJP, Van Gils JA (2012) A three-stage symbiosis forms the foundation of seagrass ecosystems. Science 336:1432-1434

Van Kooten O, Snel JFH (1990) The use of chlorophyll fluorescence nomenclature in plant stress physiology. Photosynth Res $25: 147-150$

Waycott M, Duarte CM, Carruthers TJB, Orth RJ, Dennison WC, Olyarnik S, Calladine A, Fourqurean JW, Heck KL Jr, Randall Hughes A, Kendrick GA, Judson Kenworthy W, Short FT, Williams SL (2009) Accelerating loss of seagrasses across the globe threatens coastal ecosystems. Proc Natl Acad Sci USA 106:12377-12381

Xie X, He Z, Chen N, Tang Z, Wang Q, Cai Y (2019) The roles of environmental factors in regulation of oxidative stress in plant. BioMed Res Int 2019:9732325

Yadav SK (2010) Cold stress tolerance mechanisms in plants. A review. Agron Sustain Dev 30:515-527

Publisher's Note Springer Nature remains neutral with regard to jurisdictional claims in published maps and institutional affiliations. 